\title{
Erratum to: Is time up for the Flesch measure of reading ease?
}

\author{
James Hartley ${ }^{1}$
}

Published online: 8 September 2016

(C) Akadémiai Kiadó, Budapest, Hungary 2016

\section{Erratum to: Scientometrics (2016) 107:1523-1526 DOI 10.1007/s11192-016-1920-7}

In the original publication of this paper, under the section "Some conclusions: What should we do now?" the descriptions of the 'cloze' and the 'SMOG' techniques were given incorrectly. The correct text should read:

Only tests such as the 'cloze' procedure (Taylor 1953) — where you respond to the texts in question by supplying every omitted—say-5th word count-or the 'SMOG test' (a simple measure of gobbledeygook) (McLaughlin 1969)—where you count the words with more than three syllables, can take variables such as these into account.

The online version of the original article can be found under doi:10.1007/s11192-016-1920-7.

\footnotetext{
$\square$ James Hartley

j.hartley@keele.ac.uk

1 School of Psychology, Keele University, Staffordshire, UK
} 